\title{
Dentistry, and why it is a great career
}

\author{
S. Ofori-Attah ${ }^{1}$
}

\section{In brief}

Offers guidance, motivation and encouragement to current and prospective dentists.
Reassures dentists over their career choice.

Provides reasons to go into and stay in dentistry.

The current climate of dentistry is one of sharply rising costs, increased litigation and more common placed stress, alongside the ever existing challenges that have persisted. This Opinion article looks into the reasons for embarking upon and staying within a dental career, despite the alleged drawbacks, and aims to promote a sense of positivity for the career that too often appears to be waning.

\section{Introduction}

Why did we choose to become dentists? Once I revert to my idealistic pre-undergraduate self, I could reel off several good formulaic answers. A more apt adjoining question would be: 'Why am I still a dentist?' That is, in spite of all the doom and gloom we encounter through dentistry talks, media, colleagues, websites, forums and blog posts, whether it is on the plight of the NHS, rising costs or the increase in litigation.

You don't just stumble into a job this unique: even within the realms of healthcare, dentistry stands apart. It is half business, half clinical; it is an incredibly intimate job with the potential for great impact: focusing on a part of the body that influences one's confidence, general health, how you eat, sleep, drink, talk and how you are perceived by others. So clearly some thought must have gone into the decision to take up this career.

Lest we forget public opinion: on at least one occasion, a patient will have told you, 'I hate dentists'. There are common negative stereotypes of dentists as money grabbing,

${ }^{1}$ Foxhall Road Dental Practice, 49 Foxhall Road, Ipswich, IP3 8JU

Correspondence to: Dr Samuel Ofori-Attah

Email: sammyoa@hotmail.co.uk

Refereed Paper. Accepted 8 June 2017

DOI: $10.1038 /$ sj.bdj.2017.617 fear inducing sadists - who would wish to be attached to this image?

It is a long journey too: you have sat the many exams to get into and stay in university. You have paid the exorbitant fees to complete the five years of training and to register with the regulator and an indemnity provider. Then you begin the job to learn first hand the issues with difficult patients, complaints, over regulation, rising costs, pay, stress, perpetually continuing years of training, the threat of being sued, high rate of depression and suicide and the physical demands (chronic back pain, hypertension, carpal tunnel syndrome to name a few). Adapting to the many types of people you see each day is mentally straining, along with its potentially repetitive nature.

Half of all respondents to the latest NHS Dental Working Patterns Survey ${ }^{1}$ said they often think about leaving dentistry. Seventytwo percent of associates and $81 \%$ of principals in the UK did not have high or very high morale. Just under half of all dentists surveyed in England and Wales disagreed that they were fairly paid, and these figures were greater in Scotland and greater still in Northern Ireland.

Then there are the day to day things that go wrong, which can be stressful, such as that mouth that just won't open, the battle to run on time, the admin and paperwork (which must be done contemporaneously and immaculately), broken endodontic files, failed treatment you have previously done, anxious patients, crowns not fitting, difficulty numbing a patient, repeating the same oral hygiene and diet advice, bad debts, staffing issues, broken equipment, revenue targets, UDA targets, satisfying the regulators, etc.

\section{So why choose dentistry?}

'A person has two reasons for doing anything: a good reason and the real reason. J. P. Morgan

The good reason provides an explanation to others, the real reason gets you out of bed every day. Should the reasons be both 'good' and 'real' then one may say they have a great career.

Given the breadth of minuses, there have to be some pretty good plus points to dentistry otherwise we would have long since hung up our drills and forceps to take up other careers! There have to be things that people enjoy taking away from the job, given all the hardships they have to put in to get into and stay in the career. Quite frankly there are easier, better paid jobs with the same freedoms and controls. However...

\section{For me, it's multifactorial}

There are lots of good reasons below but on their own, each could be torn apart or better found in other careers. But together, the unique manner of dentistry truly shines through, as no career path offers quite the same blend of positives. 


\section{Reasons}

\section{I want to help people}

Dental treatment really can help people. A successful root treatment or filling can help to remove pain; a denture may help people eat foods they may previously have struggled with. Dentists help people's health through treating gum disease, dental caries and related pathology. This can in turn improve their quality of life. As can the impact of changing the appearance of their teeth through teeth whitening or orthodontics. I feel that in most encounters we have with patients, we are helping them, to some extent. Even if it's simply to give them a clean bill of dental health at a routine dental visit.

This goodwill can feel great. It can come immediately on the completion of treatment when you see a patient's reaction or when you see how good the bridge or filling you have done looks. But the reason, 'I want to help people' can't be everything. It's such a short lived sensation, a few seconds at the end of a treatment - some treatments take hours to weeks to complete, which can be a lot of hard work for just a brief bit of satisfaction at the end. And not all treatment we do works, which can take a hit on morale if the end result is one's biggest motivator.

Tying your enjoyment of the job with a patient's experience and patient journey can be very satisfying for a brief moment at the end of a course of treatment - when it goes well. But it can be hugely detrimental. You end up riding that patient journey with them: you may feel their anxiety over the treatment or the pricing, you will feel their disappointment if the treatment has not gone well and you have ultimately failed to help them or their relief that it is all over. There have to be stronger reasons to go with the 'helping people' one for it to work in reality.

\section{I like the end result - compared to art, science research, musician, TV and film}

Looking at a well-obturated molar tooth or admiring a completed smile makeover you've done can be very satisfying and rewarding. We cannot pin all our enjoyment of the job on the end result. There has to be some enjoyment of the process. Otherwise we'll feel every failure and every bit of disappointment the patient experiences. Compare it to a scientist researching a cure for cancer or a musician writing an album. The scientist probably cannot derive all their job satisfaction from the end result, as they may never get there. As a musician myself, I get immense pleasure from the process: the sound produced playing a sequence of notes and the harmonies upon hearing a chord or playing with other musicians. The joy does not necessarily come when I have completed a song or concert or reached whatever end goal I have set.

The long term impact of our treatment is questionable too. We may feel great doing these life-changing smile makeovers and feel like we are really improving a patient's quality of life or self well being. However, there is strong research to say our level of self-happiness returns to the same level after a life changing positive event. This is made more interesting when in contrast, life-changing negative events tend to have a greater negative effect on our base line level of happiness than positive events have on the base line level. Think of all those patients who come in saying they 'hate dentists' and further conversation reveals this 'hate' stems from a bad experience. We don't as often get people coming in saying they 'love dentists' as a result of a positive experience.

Happiness, its permanence and hedonism are complex topics that alone could provide one with a dissertation's worth of discussion but thankfully the likes of Brickman et al. (1978), ${ }^{2}$ Lucas, Clark, Georgellis and Diener (2003), ${ }^{3}$ Headey (2008) ${ }^{4}$ and others have already walked that path.

\section{Lifelong relationships with patients/ working with people}

Dentistry wouldn't really be the same without the patients, so it's definitely a good career for those who like to meet new people and develop relationships with them. It's wonderful when you see people throughout different stages of their year: birthdays, Christmas, holidays and also through different stages of their lives: births, weddings, leaving school, new job etc.

If you enjoy talking and listening to people, you will get to do this a lot as a dentist. When you see a person or a family regularly enough, you end up becoming part of their lives and part of your community.

\section{For the artistic side}

One definition of dentistry is that it is, 'the art and science of oral health. The British Dental Association (BDA) have used the motto that they are here to 'promote the art and science of dentistry'. We often think of it as a science but there is definitely an artistic element, from shaping a white filling on an anterior tooth to realigning a whole arch.

Admittedly, the artistic boundaries are limited to what is anatomically and ethically reasonable: a dentist is unlikely to unleash the full extent of their artistic side on a patient by turning their teeth into a surrealist sculpture. But some of the characteristics of sculpturing, for example the precision, the respect paid to symmetry and cosmetics, are shared with dentistry.

\section{For the money - financial independence}

I am not sure I would do this job purely for the money. Well the money is good, it's very good. There aren't many careers where graduates earn over $£ 33,000$ in their first year. Medics certainly don't. By your second year of work, you may earn between $£ 50,000$ to $£ 70,000$, the latter figure being where the current average dentist's earnings lie. ${ }^{5}$ With an income at that level, financial independence seems very feasible. Then work hard enough, invest in the right training, practice, give it some time and the earning potential goes even further. Therein lies the issue of the money being a great reason to choose dentistry. It is not easy money - you have to work hard to meet your NHS targets, your revenue targets and your patients' wishes. You have to invest a lot of money back into your job, be it lab bills, overheads, training, indemnity or the GDC retention fee, so that handsome $£ 5,800$ a month soon gets whittled down. You will struggle to get through each day if you do not find something positive to take from the job, barring money.

It's a competitive career, particularly at university level. You have to work hard to get onto and stay on the five to six year course. To get onto the course, you have to be fairly academic and get good grades. These same grades could land you on a shorter bachelors or masters degree that may lead to a job in law, banking, finance or the tech industry, all of which may lead to higher financial returns.

\section{Career independence}

Self-employed. Pension. For the lifestyle: job security, hours

So the money is very good but there are jobs that offer higher incomes. What are the other financial benefits then, if any? In industries such as law, banking, finance and the tech industry, you will most likely be employed - especially in your early years. Being self-employed gives you a lot of freedom on where you can work, 
how much you work a week or a year and the opportunity to take career breaks. Working with the NHS gives you a generous pension and, provided targets are met, a steady income each month.

You have a lot of control in how you wish to work, from the choice of equipment, material and dental lab to staff and premises.

There will always be teeth so there will always be a need for dentists. The nature of our job may change and how we are paid but there will be employment. It's unlikely that machines will be able to do our job and it would take a brave government to completely remove the provision of NHS dental care.

Despite the ever increasing competition for jobs, it is still pretty difficult for UK graduates with a performer number to find themselves without a job. It may not be exactly where you want but there seems to be enough work out there for general dentists. So it is a secure career - at least for now.

\section{For the love of dental science}

This for me is the only reason that truly stands up on its own as a reason to do dentistry. No matter how bad things get with the administrative, business, stress or clinical side, you will always have dental science at the core of what you do. And if you like it you get to wake up every day with the knowledge that it will be at the heart of every treatment or bit of dental advice you impart that day. Nothing can take that away. I'm not saying you need to love teeth or gums or dental drills. That would be strange; saying, 'I love teeth' is akin to a plumber saying 'I love toilets'. But dental science, how teeth form, the theory behind demineralisation, the anatomy, the physiology, the oral biology... there is some interesting stuff in there.

I was never really big on the material sciences but I can appreciate those who are. I have met hundreds of dentists but could probably count on one hand those that truly like dental science. And I envy them, I truly do. I recall overhearing two colleagues discussing the light refraction indexes of two composite filling materials and being in awe. Not in awe of the conversation's content but of the sheer excitement and genuine enthusiasm they had that I may never replicate.

Yes, you could derive some of this satisfaction in a research career or as a sales rep but to truly appreciate dental science, you will want to see it in action, you want to see it at work on a patient, your patients. Only a dentist gets this privilege.
Do we have to love or even like dental science? Do ophthalmologists have to like ophthalmology? ENT doctors and otorhinolaryngology? No, but it would help.

\section{To enter into dental research,} academia or dental specialties

Well if you're interested in dental science and you have already made up your mind that a dental research or academic job rather than a patient-centred one is best for you then you have a pretty strong reason to enter this career.

Similarly, if you have decided that specialising in a certain field, such as orthodontics, is the end goal for you then a career in dentistry is the pathway there.

\section{Want to get into healthcare/was a choice over medicine and dentistry and dentistry won}

It's a strong reason. Dentistry fits firmly into the category of healthcare as a job. There are other routes one can go down after attaining their dentistry qualifications: academia, education, research and cosmetics for example. But if it's a job in healthcare you want, dentistry can definitely provide it. It is quite a niche area of healthcare though. Nursing offers a faster route into healthcare and does away with a lot of the business elements of dentistry. Medicine offers a wider range of healthcare and potentially greater impact on people's health.

\section{Like doing things with my hands}

This follows on nicely from the last point: from the get go, dentistry is very hands-on. More so than medicine. For the first three years of a medical school, most medics do not perform surgical procedures on patients. Some will do very few in their entire undergrad course. And this may carry over into their foundation training, general practice and a medical career, should they forgo the option for a surgical one. We do so much with our hands, be it intricate wax work with dentures or sculpting teeth with composite filling material.

Engineering is an obvious choice for those who like to do things with their hands but a lot of the top jobs in this field do not offer that much hands-on engineering once the degree is over. Much of it is management, planning and design.

That said, there are plenty of other careers that appeal to those wising to work with their hands such as art, construction, sport, jewellers, beauticians, hairdressers, fashion, plumbers, electricians to name a few.

\section{The status and professional recognition}

This will always be subjective but in my general experience upon people learning I am a dentist (barring the typical covering of one's mouth or immediate request for dental advice) is overwhelmingly positive. Some may say they 'hate dentists' or at least the experience of going to the dentist but they identify it as a respectable profession, one requiring higher education and expertise. And it is in this country, by the strictest definition, a profession: a self regulated industry.

\section{I watched someone else do it, family, friends, work experience and it inspired me to do the same}

I often hear this reason given and it makes perfect sense why: an influential person imparting their feelings on another can have a big impact on our decision making. Then seeing said person at work doing the work we may be able to one day do can really have an effect. This is particularly powerful if this person is a parent.

These second generation dentists are in an invaluable position to gain true insight into the career and are thus likely to have picked the right career.

\section{I had a memorable experience with a dentist as a patient}

I wish I could have phrased that better, as it sounds more like an account of a sordid episode with a dentist. That aside, it is a commonly given reason. Often bad experiences, extractions or braces trigger this early interest in dentistry. Some at the undergraduate interview shared theirs with me at the time. I had my own: I was eight-years-old and had an extraction of a deciduous molar in Ghana. It was horrific. The 'practice' looked more like the set of 'One Flew Over the Cuckoo's Nest', with the army of nurses there to hold me down all wearing the classic nurses attire. The screams of grown men that I could hear prior to my own turn were ominous. The anaesthetic was of questionable origin and certainly had no effect. How did this encourage me to become a dentist? It wasn't some altruistic urge in me that I would travel back to this practice riding a white horse wearing shining armour to deliver them from their dental despair. It was more that it was one of my only experiences I had with a dentist. It got me thinking about dentistry for the first time: what it was all about, what dentists did, how things worked. 


\section{Conclusion}

There may well be other reasons: 'My parents recommended it', 'I am a sadist,' or 'I was inspired by watching Marathon Man and Little Shop of Horrors', but the reasons I have shared above consistently seem to be coming up in my observations.

During this research, an interesting conclusion could be drawn that dentistry may be the best job for some people, given how well many of the reasons listed apply to them. However, it may not be their perfect job. Perfection evades the necessity to be practical and realistic. My perfect job would be racing Formula One cars on a weekend, writing and directing films for the big screen during the week and performing music to sell-out crowds across the globe. Granted all three simultaneously is somewhat ambitious but one of those pursuits wouldn't have been unthinkable at certain stages of my life. But could any one of those match the attainability of dentistry? No.

I'm not going to pretend that everything in dentistry is great. Some of those aspersions cast at the beginning of this article are a constant bane that may take out any of the joy from the job.

If you still don't feel clinical dentistry is for you, there are several other routes within the industry that you may go down, whether its research, teaching, academia, consulting, business or management related. Not a week goes by where I pick up a dental publication or visit a website showing an entrepreneurial dentist with a new idea I'd never thought of such as a new orthodontic retention system or social networking database. At the very least, dentistry may give you a comfortable enough income to either work part time and pursue other interests on your day off or launch other business ventures.

I considered one dichotomy of thoughts in respect to work ethic with a friend recently. We discussed two dentists, Ali and Jamie. Ali likes to do more challenging and interesting things each day, even if it means more stress when things do not go well. Jamie prefers doing simpler treatments, even if they are more repetitive, uninteresting and unchallenging, as Jamie wants a more stress free day. If you truly like the job you're doing, you won't want to be doing the same repetitive things - you'll want to push and challenge yourself, try and explore new areas of the job. Whereas if you did not, like Jamie, you just want to get through each working day stress free. This may be fine for a while but to really get the best return, find something else within the job that you can enjoy, which may in turn beneficially impact that patients you treat and the staff around you.

How many end up in their perfect job? Furthermore, how many are fortunate enough to end up in a job that is best for them? A privileged few perhaps. But given the collection of reasons to do dentistry, it would be a hard fact to dispute that as a dentist, we have all at the very least found ourselves in a great career.

1. Health and Social Care Information Centre. Dental Working Hours, 2014-15, 2015-16. Motivational Analysis, September 2016

2. Brickman P, Coates D, Janoff-Bulman R. Lottery winners and accident victims: is happiness relative? J Pers Soc Psychol 1978; 36: 917-927.

3. Lucas R E, Clark A E, Georgellis Y, Diener E. Reexamining adaptation and the set point model of happiness: Reactions to changes in marital status. J Pers Soc Psychol 2003; 84: 527-539.

4. Headey B. Life goals matter to happiness: a revision of set-point theory. Soc Indic Res 2008; 86: 213-231.

5. Health and Social Care Information Centre. Dental Earnings and Expenses, 2014/15. September 2016. 